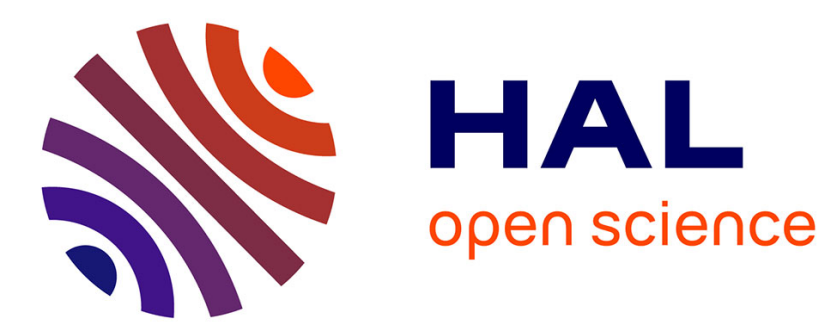

\title{
Distinct Regulation of B-type Natriuretic Peptide Transcription by p38 MAPK Isoforms
}

Elina Koivisto, Leena Kaikkonen, Heikki Tokola, Sampsa Pikkarainen, Jani

Aro, Harri Pennanen, Teemu Karvonen, Jaana Rysä, Risto Kerkelä, Heikki

Ruskoaho

\section{To cite this version:}

Elina Koivisto, Leena Kaikkonen, Heikki Tokola, Sampsa Pikkarainen, Jani Aro, et al.. Distinct Regulation of B-type Natriuretic Peptide Transcription by p38 MAPK Isoforms. Molecular and Cellular Endocrinology, 2011, 10.1016/j.mce.2011.02.015 . hal-00693834

\section{HAL Id: hal-00693834 https://hal.science/hal-00693834}

Submitted on 3 May 2012

HAL is a multi-disciplinary open access archive for the deposit and dissemination of scientific research documents, whether they are published or not. The documents may come from teaching and research institutions in France or abroad, or from public or private research centers.
L'archive ouverte pluridisciplinaire HAL, est destinée au dépôt et à la diffusion de documents scientifiques de niveau recherche, publiés ou non, émanant des établissements d'enseignement et de recherche français ou étrangers, des laboratoires publics ou privés. 


\section{Accepted Manuscript}

Title: Distinct Regulation of B-type Natriuretic Peptide Transcription by p38 MAPK Isoforms

Authors: Elina Koivisto, Leena Kaikkonen, Heikki Tokola, Sampsa Pikkarainen, Jani Aro, Harri Pennanen, Teemu Karvonen, Jaana Rysä, Risto Kerkelä, Heikki Ruskoaho

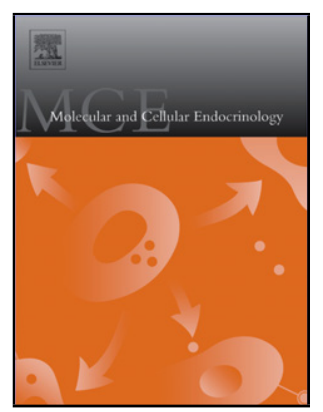

PII:

DOI:

S0303-7207(11)00152-3

Reference: doi:10.1016/j.mce.2011.02.015

To appear in: $\quad$ Molecular and Cellular Endocrinology

Received date: $\quad$ 23-12-2010

Revised date: 27-1-2011

Accepted date: $\quad$ 17-2-2011

Please cite this article as: Koivisto, E., Kaikkonen, L., Tokola, H., Pikkarainen, S., Aro, J., Pennanen, H., Karvonen, T., Rysä, J., Kerkelä, R., Ruskoaho, H., Distinct Regulation of B-type Natriuretic Peptide Transcription by p38 MAPK Isoforms, Molecular and Cellular Endocrinology (2010), doi:10.1016/j.mce.2011.02.015

This is a PDF file of an unedited manuscript that has been accepted for publication. As a service to our customers we are providing this early version of the manuscript. The manuscript will undergo copyediting, typesetting, and review of the resulting proof before it is published in its final form. Please note that during the production process errors may be discovered which could affect the content, and all legal disclaimers that apply to the journal pertain. 


\title{
Distinct Regulation of B-type Natriuretic Peptide Transcription by p38 MAPK Isoforms
}

\author{
Elina Koivisto ${ }^{\text {a, }}$, Leena Kaikkonen ${ }^{\text {a, } 1}$, Heikki Tokola ${ }^{\text {a, b }}$, Sampsa Pikkarainen ${ }^{\text {a }}$, Jani Aro ${ }^{\text {a }}$, Harri Pennanen ${ }^{\text {a }}$ \\ Teemu Karvonen ${ }^{a}$, Jaana Rysä ${ }^{a}$, Risto Kerkelä ${ }^{a}$ and Heikki Ruskoaho ${ }^{\mathrm{a}, *}$ \\ ${ }^{a}$ Institute of Biomedicine, Department of Pharmacology and Toxicology, P.O.Box 5000, FIN-90014 \\ Biocenter Oulu, University of Oulu, Finland \\ ${ }^{\mathrm{b}}$ Institute of Diagnostics, Department of Pathology, P.O.Box 5000, FIN-90014 University of Oulu, Finland \\ ${ }^{1}$ These authors contributed equally to this work \\ *Corresponding author. Tel.: +358-8-5375236; fax: +358-8-5375247. E-mail address: \\ heikki.ruskoaho@oulu.fi (H. Ruskoaho).
}

Running head: Distinct regulation of BNP by p38 isoforms in cardiomyocytes

\begin{abstract}
Persistent controversy underlies the functional roles of specific p38 MAPK isoforms in cardiac biology and regulation of hypertrophy-associated genes. Here we show that adenoviral gene transfer of $p 38 \beta$ but not $p 38 \alpha$ increased B-type natriuretic peptide (BNP) mRNA levels in vitro as well as atrial natriuretic peptide mRNA levels both in vitro and in vivo. Overexpression of $\mathrm{p} 38 \alpha$, in turn, augmented the expression fibrosis-related genes connective tissue growth factor, basic fibroblast growth factor and matrix metalloproteinase- 9 both in vitro and in vivo. p38 $\beta$-induced BNP transcription was diminished by mutation of GATA- 4 binding site, whereas overexpression of MKK6b, an upstream regulator of $\mathrm{p} 38 \alpha$ and $\mathrm{p} 38 \beta$, activated BNP transcription through both GATA-4 and AP-1. Overexpression of MKK3, upstream regulator of p38 $\alpha$, induced BNP transcription independently from AP-1 and GATA-4. These data provide new evidence for diversity in downstream targets and functional roles of p38 pathway kinases in regulation of hypertrophy-associated cardiac genes.
\end{abstract}

Key words: BNP; MAP kinases (MAPKs); p38 MAPK; Cardiac hypertrophy; AP-1; GATA-4

Abbreviations: aFGF, acidic fibroblast growth factor; ANP, atrial natriuretic peptide; AP-1, activator protein1; ATF-2, activating transcription factor-2; bFGF, basic fibroblast growth factor; $\beta$-MHC, $\beta$-myosin heavy chain; BNP, B-type natriuretic peptide; COL1A1, collagen type I alpha; CTGF, connective tissue growth factor; DN, dominant negative; ERK, extracellular signal-regulated protein kinase; ET-1, endothelin-1; MAPK, mitogen-activated protein kinase; MKK3, mitogen-activated protein kinase kinase 3; MKK6, mitogen-activated protein kinase kinase 6; MMP-2, matrix metallo-proteinase-2 (MMP-2); MMP-9 matrix metalloproteinase-9; PE, phenylephrine; PDGF-A, platelet-derived growth factor alpha polypeptide; WT, wild type 


\section{Introduction}

Natriuretic peptides atrial natriuretic peptide (ANP) and B-type natriuretic peptide (BNP) are cardiac hormones released into circulation by myocytes to protect the cardiovascular system against increased hemodynamic load and decrease blood pressure by increasing salt and water excretion and by promoting vasodilatation (reviewed in de Bold et al., 1996; Ruskoaho, 2003; Kuwahara and Nakao, 2010). Increased expression of natriuretic peptides is a sign of hemodynamic overload of the heart and, at least in experimental setting, can be used to measure the hypertrophic response in the heart. A number of signalling pathways are implicated in the regulation of hypertrophy-associated genes, such as ANP and BNP. Among these are mitogen-activated protein kinases (MAPKs), which represent a central converge point regulating cellular behaviour. The three most-characterized MAPK pathways are the extracellular signal regulated kinases (ERKs), the c-Jun N-terminal kinases (JNKs) and the p38s (Kyriakis and Avruch, 2001; Wang, 2007).

The p38 MAPK is a serine-threonine kinase that was originally isolated as 38-kDa protein rapidly phosphorylated in response to lipopolysaccharide stimulation (Han et al., 1993; Han et al., 1994). It activates numerous downstream kinases and transcription factors via phosphorylation (Ono and Han, 2000; Tenhunen et al., 2006). p38 MAPK is in turn phosphorylated and hence activated by two upstream MAP kinase kinases (MAPKKs, or MKKs), MKK3 (Derijard et al., 1995) and MKK6 (Han et al., 1996). Of the four p38 isoforms $(\alpha, \beta, \gamma$ and $\delta$ ), only $\mathrm{p} 38 \alpha$ and $\mathrm{p} 38 \beta$ isoforms are substantially expressed in heart (Jiang et al., 1996; Li et al., 1996; Jiang et al., 1997). Selective activation of different p38 isoforms by distinct MKKs has also been observed; MKK6, which is $80 \%$ homologous to the isoform MKK3, can activate all four p38 isoforms,

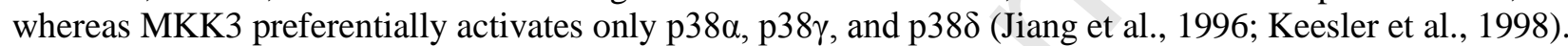

p38 MAPK plays a central role in cardiac pathology, but controversy over the exact role - detrimental or beneficial - still exists. Several in vitro and in vivo studies indicate that $\mathrm{p} 38$ is an important regulator of cardiac hypertrophy (reviewed in Wang, 2007), but contradictory evidence has also been presented. For example, MKK6-overexpressing hearts exhibited reduced end-diastolic ventricular cavity size and a modest increase in cardiomyocyte size, while MKK3-overexpressing hearts had increased end-systolic chamber volumes and thinned ventricular wall associated with myocyte atrophy (Liao et al., 2001). On the other hand, dominant negative (DN) p38 $\alpha$, DN MKK3b and DN MKK6b transgenic mice showed progressive cardiac hypertrophy, also suggesting an anti-hypertrophic function of p38 MAPK (Braz et al., 2003). We previously found that in vivo adenoviral overexpression of MKK3b together with $\mathrm{p} 38 \alpha$ led to a marked functional improvement in infarcted rat heart; the size of an infarction area was significantly reduced, apoptosis decreased and angiogenesis increased (Tenhunen et al., 2006). In addition, Nishida et al. showed that cardiac-specific knockdown of p38 $\alpha$ led to increased cardiomyocyte apoptosis and adverse myocardial remodelling following pressure overload (Nishida et al., 2004). However, several studies have demonstrated that during myocardial ischemia, p38 MAPK inhibition protects against lethal injury (Saurin et al.,2000; Bassi et al., 2008).

The main reason for these controversial results may be both the overlapping and distinct physiological functions of p38 MAPK isoforms (reviewed in Bassi et al., 2008). Wang et al. have suggested that p38a (with MKK3b) might have pro-apoptotic effects while the overexpression of the p38 $\beta$ (with MKK6b) isoform results in a hypertrophic response of cultured cardiac myocytes (Wang et al., 1998). These findings were reiterated by Saurin et al., who demonstrated that inhibition of the p38 $\alpha$ isoform, and not p38 $\beta$, led to an increase in cell viability and protection (Saurin et al., 2000). While novel pharmacological compounds are already in trials targeting p38 MAPK in cardiovascular diseases, undoubtedly more information about p38 downstream molecules, and especially about the possible differences between the $\mathrm{p} 38$ isoforms, is needed to determine whether the pharmacological manipulation of p38 MAPK pathway is a valid approach to treat cardiac pathologies.

In this study we investigated the specific functions of $\mathrm{p} 38 \alpha$ and $\mathrm{p} 38 \beta$ and their downstream targets in cardiomyocytes. We find remarkable differences in p38 MAPK isoforms in regulating hypertrophyassociated genes ANP and BNP as well as genes involved in cardiac fibrosis. Further, we show that while $\mathrm{p} 38 \alpha$ induces BNP transcription via activator protein-1 (AP-1), the $\mathrm{p} 38 \beta$-induced BNP transcription is mediated by transcription factor GATA-4. We also dissected the roles of upstream MAPKKs of p38 pathway and define novel downstream target genes of the specific p38 MAPK isoforms.

\section{Materials and methods}




\subsection{Materials}

Cell culture reagents (bovine serum albumin, $\mathrm{CaCl}_{2}, \mathrm{DMEM} / \mathrm{F}-12, \mathrm{PBS}$, insulin-transferrin sodiumselenite media supplement, L-glutamine, penicillin-streptomycin, sodium pyruvate, 3' 3' $3^{\prime} 5^{\prime}$-triiodo-Lthyronine), endothelin-1 (ET-1), phenylephrine (PE), anti-flag antibody, protease- and phosphatase- inhibitor cocktails (used in protein extraction) and protein extraction detergent IGEPAL ${ }^{\circledR}$ CA-630, as well as all the oligonucleotides were from Sigma-Aldrich (St. Louis, MO, USA). Antibodies against MKK3 and MKK6 were from Santa Cruz Biotechnology Inc (Santa Cruz, CA, USA). Antibody against phospho-p38 (Thr180/Tyr182) and collagenase type II Worthington (used in cell culture) were from Millipore (Billerica, MA, USA). The p38 kinase assay kit containing also phosphorylated activating transcription factor-2 (phospho-ATF-2) antibody as well as antibody against total p38 was from Cell Signaling Technology (Danvers, MA, USA). A p38 inhibitor SB203580 was from Tocris Bioscience (Bristol, UK). ECL Plus ${ }^{\mathrm{TM}}$ Western Blotting Detection System reagents, First-Strand cDNA Synthesis Kit for RT-qPCR and and L-[4,5$\left.{ }^{3} \mathrm{H}\right]$ leucine were from GE Healthcare (Waukesha, WI, USA). Bio-Rad Protein Assay was from Bio-Rad Laboratories (Hercules, CA, USA) and cell culture plates were from Greiner Bio-one (Monroe, NC, USA). Dual-Luciferase ${ }^{\circledR}$ Reporter Assay System and pRL-TK control expression plasmid were from Promega Co. (Fitchburg, WI, USA) and FuGENE 6 transfection reagent was from Roche Applied Science (Penzberg, Germany).

\subsection{Adenoviral vectors and plasmids}

Adenoviral vectors encoding p38 MAPK pathway proteins were generated as described (Wang et al., 1998) and BNP promoter constructs as reported earlier (Pikkarainen et al., 2002; Pikkarainen et al., 2003). Further details about recombinant adenoviruses and BNP constructs are presented in Supplementary Materials and Methods.

\subsection{Cell culture and transfections}

Cells were prepared from 2- to 4-day-old Sprague-Dawley rats as described (Tokola et al., 1994). Cultured cells were subjected to transfection of the plasmid containing intact -534 BNP or mutated -534 BNP -luc-constructs along with pRL-TK control plasmids ( $1 \mu \mathrm{g}$ and $0.5 \mu \mathrm{g}$, respectively) as described earlier (Pikkarainen et al., 2002). Adenoviruses were added to the culture medium approximately 18-24 hours after the cells were plated and incubated for 24 hours, at the virus concentration of 1 to 4 MOI (depending on the designed experiment). In co-transduction experiments, recombinant adenoviruses were added to the culture medium 6-8 hours after the plasmid insertion, and incubated for 24 hours. When appropriate, ET-1 (100 nM for 24 hours) or PE (100 $\mu \mathrm{M}$ for 15 minutes) were added to culture medium at the third day of culture. pRL-TK plasmid was used as a control vector of BNP transfected cells in each sample to equalize for transfection efficacy and the data are presented as ratio of luciferase activity to pRLTK activity. A luminometer (model RS from Thermo Labsystems, Vantaa, Finland) was used to measure luminescence.

\subsection{Western blot and kinase assays}

Protein extraction and Western blot analysis were performed as described (Kerkela et al., 2002; Pikkarainen et al., 2003). For kinase assay, myocytes were collected by scraping them into $200 \mu 1$ of cell lysis buffer. The phosphorylated p38 was immunoprecipitated with specific antibody at $4{ }^{\circ} \mathrm{C}$ overnight. Next day, the immunoprecipitates were washed twice with cell lysis buffer after centrifugations (10 $000 \mathrm{rpm})$, and then once more with a kinase buffer. After the final centrifugation, the pellets were incubated for $30 \mathrm{~min}$ at $30^{\circ} \mathrm{C}$ with kinase buffer, $200 \mu \mathrm{M}$ ATP and $\left.2 \mathrm{mg} / \mathrm{ml} \mathrm{ATF-2} \mathrm{fusion} \mathrm{protein} \mathrm{as} \mathrm{a} \mathrm{substrate} \mathrm{(} 50 \mu 1 / \mathrm{sample}\right)$. All reagents were from Cell Signaling Technology. The reactions were terminated by placing the samples on ice and adding $10 \mu 1$ of 5xSDS. The samples were then boiled, microcentrifuged and analyzed by Western blotting for phosphorylated ATF-2.

\subsection{Isolation and analysis of RNA}


The RNA was extracted from cardiomyocytes with TRIzol reagent following the manufacturer's protocol (Invitrogen, Carlsbad, CA, USA) using the Phase Lock Gel System (Eppendorf AG, Hamburg, Germany) and analyzed by real-time reverse transcription (RT) QPCR. cDNA first strand was synthesized from total RNA derived from neonatal ventricular myocytes. Rat ANP, BNP, $\beta$-myosin heavy chain ( $\beta$-MHC), connective tissue growth factor (CTGF), acidic fibroblast growth factor (aFGF), basic fibroblast growth factor (bFGF), collagen type I alpha 1 (COL1A1), matrix metallo-proteinase-2 (MMP-2), matrix metalloproteinase-9 (MMP-9) and platelet-derived growth factor alpha polypeptide (PDGF-A) mRNA levels were measured by RT-PCR as previously described (Majalahti-Palviainen et al., 2000). The primers and fluorogenic probes used in real-time RT-QPCR are presented in Supplementary Table S1. The results were normalized to $18 \mathrm{~S}$ quantified from the same samples.

\subsection{Protein synthesis}

$\left[{ }^{3} \mathrm{H}\right]$ leucine incorporation was measured as described previously (Berk et al., 1989). Briefly, cells were cultured in 24-well plates. When appropriate, recombinant adenoviruses were added to culture medium on a second day of culture. On a third day of culture, medium was replaced with CSFM supplemented with $\left[{ }^{3} \mathrm{H}\right]$ leucine $(5 \mu \mathrm{Ci} / \mathrm{ml})$. After 24 hours, cells were lysed and processed for measurement of incorporated $\left[{ }^{3} \mathrm{H}\right]$ leucine by liquid scintillation counter.

\subsection{Cell death assays}

Analysis for determination of cytoplasmic histone-associated DNA fragments was performed according to manufacturer's instructions (ELISA ${ }^{\text {PLUS }}$ Cell Death Detection Kit, Roche Applied Science, Penzberg, Germany). Examination of the release of adenylate kinase from ruptured cells into the cell culture medium was carried out with bioluminescent ToxiLight ${ }^{\circledR}$ Bioassay kit (Lonza Rockland Inc, Rockland, ME, USA) kit according to manufacturer's instructions (Kerkela et al., 2006).

\subsection{Cardiac gene transfer in vivo}

Male Sprague-Dawley rats weighing 250-300 g $(n=40)$ were used. Cardiac gene transfer of recombinant adenoviruses (LacZ, wild type p38 $\alpha$ or wild type p38 $\beta$ and constitutively active MKK3b or MKK6b) into the left ventricular free wall was performed as previously described (Tenhunen et al., 2006). After three days, the animals were killed, the hearts were removed, and the cardiac chambers were separated. Left ventricular tissue samples were weighed, immersed in liquid nitrogen, and stored at $-70^{\circ} \mathrm{C}$ for later analysis. Extraction of RNA was performed as previously described (Tenhunen et al., 2004) and mRNA levels of ANP, CTGF, bFGF and MMP-9 mRNA levels were measured by RT-QPCR. The experimental design was approved by the Animal Use and Care Committee of the University of Oulu.

\subsection{Statistical analysis}

Results are expressed as means \pm SEM For the comparison of statistical significance between two groups, the Student's $t$ test was used. For multiple comparisons, data were analyzed with one-way analysis of variance followed by a least significant difference (LSD) post hoc test. Differences at the $95 \%$ level were considered statistically significant.

\section{Results}

\subsection{Function of recombinant adenoviruses and p38 inhibitor SB203580}

Neonatal rat cardiomyocytes were transduced with recombinant adenoviruses encoding either wild type (WT) p38 $\alpha$ or WT p38 3 . The transduction efficacy was confirmed with a specific antibody recognizing the fusion proteins of WT p38 $\alpha$ and WT p38 $\beta$ that contain a flag-epitope (-Asp-Tyr-Lys-Asp-Asp-Asp-Asp-Lys). Western blot analysis showed similar transduction of WT p38 $\alpha$ and WT p38 $\beta$ to the cells detected by antiflag antibody (representative Western blot is shown in Supplementary Figure S1 A). Next, the p38 kinase 
activity following adenoviral transfer of p38 MAPK isoforms was determined by kinase assay. Cell lysates were immunoprecipitated with phospho-p38 antibody, and the phosphorylation rate of downstream target ATF-2 was detected with specific antibody by Western blotting. We found that the ATF-2 phosphorylation was similarly enhanced by both WT p38 $\alpha$ and WT p38 $\beta$ indicating similar kinase activity (representative Western blot is presented in Supplementary Figure S1 B).

Cultured cardiomyocytes were then transduced with adenoviruses carrying sequences for constitutively active forms of MKK3b and MKK6b [MKK3b(E) and MKK6b(E), respectively]. The transduction efficacy was confirmed with MKK3 and MKK6 antibodies by Western blotting (representative Western blots are shown in Supplementary Figure S1 A). ATF-2- based kinase assay demonstrated that overexpression of both MKK3b(E) and MKK6b(E) with or without WT p38 $\alpha / \mathrm{p} 38 \beta$ markedly induced ATF-2 phosphorylation (representative Western blots are shown in Supplementary Figure S1 B). In addition, both upstream MKKs (MKK3 or MKK6) similarly enhanced the activity of the p38 isoforms. However, because prior data suggests that $\mathrm{p} 38 \alpha$ is regulated by MKK3, and $\mathrm{p} 38 \beta$ by both MKK3 and MKK6 (Jiang et al., 1996; Keesler et al., 1998), we selected to use combinations of WT p38 $\alpha+$ MKK3b(E) and WT p38 $\beta+$ MKK6b(E) to maximally induce the activation of p38 isoforms.

We also transduced the cardiomyocytes with dominant negative (DN) p38 $\alpha$ or DN p38 $\beta$ and treated the cells with PE, a potent hypertrophic agonist acting via G-protein coupled receptors (GPCR) (Simpson,1985). PE $(100 \mu \mathrm{M})$ evoked a 13.8-fold increase in downstream target ATF-2 phosphorylation levels. DN p38 $\alpha$ reduced the PE-induced ATF-2 phosphorylation by $87 \%$ and DN p38 $\beta$ by $90 \%$, hence suggesting that adenoviral DN p38 $\alpha$ and DN p38 $\beta$ are both equally capable of inhibiting the PE-induced activation of the kinases (Supplementary Figure S2 A). The amount of phosphorylated p38 MAPK in cardiomyocytes was also reduced to similar extent by transduction of cells with DN p38 MAPKs (Supplementary Figure S2 B). The function of pharmacological p38 inhibitor SB203580 was analyzed with ATF-2 -based kinase assay as well. We found that SB203580 $(10 \mu \mathrm{M})$ reduced the PE-induced ATF-2 phosphorylation by $81.5 \%$ (Supplementary Figure S2 C).

\section{2. $p 38 \alpha$ and $p 38 \beta M A P K$ regulate the hypertrophic response of cardiomyocytes}

To investigate the role of p38 in cardiac hypertrophy, we studied the effect of p38 on BNP and two to other central hypertrophy-associated genes ANP and $\beta$-MHC. Our data demonstrates that only $\mathrm{p} 38 \beta$ isoform (with upstream kinase MKK6) significantly induced the transcription of ANP (3.5-fold, $P<0.001)$ and BNP ( 2.8 -fold, $P<0.01$ ) and it also tended to increase $\beta$-MHC transcription. Instead, $\mathrm{p} 38 \alpha$ did not significantly induce any of the genes studied, but, on the contrary, significantly diminished the $\beta$-MHC mRNA levels (by $78 \%, P<0.001$ ) (Fig. 1A-C). Instead, both p38 isoforms induced an increase in protein synthesis, another hallmark feature of cardiomyocyte hypertrophy (Sugden and Clerk, 1998), alone or in combination with upstream MKKs, without significant differences between the isoforms (Fig. 1D). Protein synthesis was increased also by transduction of MKK3 or MKK6 alone (Fig. 1D).

\section{3. $p 38 \alpha$ and $p 38 \beta$ regulate BNP promoter via distinct pathways}

Next, ET-1, a powerful paracrine inducer of cardiomyocyte growth and hypertrophy (Shubeita et al., 1990), was used to activate rat BNP reporter gene transcription. ET-1 (100 nM) induced a 2.3-fold increase in rat $(\Delta-534 /+4)$ BNP promoter luciferase construct (rBNP-luc) transcription $(P<0.001)$. Interestingly, coexpression of DN p38 $\beta$ in rBNP-luc transfected cardiomyocytes completely abolished the ET-1-induced rBNP promoter activation, whereas overexpression DN p38 $\alpha$ had no significant effect (Fig. 2A). However, overexpression of both WT $\mathrm{p} 38 \alpha$ and WT $\mathrm{p} 38 \beta$ significantly activated the rBNP promoter $(P<0.001$ and $P<0.01$, respectively, Fig. 2B).

The downstream targets of $\mathrm{p} 38$ MAPK isoforms were further studied by reporter gene assays. Cardiomyocytes were transfected with rBNP promoter construct containing two site-directed mutations of the proximal GATA-4 sites (BNP GATAMut). Interestingly, p38 $\beta$-induced increase in rBNP promoter activity was significantly reduced by mutation of GATA-4 binding sites $(P<0.05$, Fig. $2 \mathrm{C})$. In contrast, p38 $\alpha$-induced rBNP activation was not affected by the GATA- 4 binding site mutation. Previous studies suggest functional cooperation between GATA-4 and AP-1 in pressure overload-induced hypertrophy (Herzig et al., 1997). To investigate the importance of AP-1 binding site in p38-induced BNP promoter activation, we introduced a site directed mutation at AP-1 binding site of rBNP promoter (BNP AP-1Mut). 
Intriguingly, $\mathrm{p} 38 \alpha$-induced $\mathrm{rBNP}$ promoter activation was diminished by mutation of AP-1 binding site, whereas $\mathrm{p} 38 \beta$-induced $\mathrm{rBNP}$ reporter activation was not affected $(P<0.05$, Fig. 2D). Finally, since ANP, BNP and $\alpha-\mathrm{MHC}$, contain potential ETS binding sequences (EBS) in their regulatory region (Pikkarainen et al., 2003; Gupta et al., 1998), and previous studies have suggested that overexpression of p38 $\alpha$ results in EBS-dependent activation of rBNP promoter activity (Pikkarainen et al., 2003), we introduced a site directed mutation at EBS site of rBNP promoter. However, the activation of rBNP reporter induced by overexpression of WT p38 $\alpha$ or WT p38 $\beta$ was not affected by the mutation of EBS at $-498 \mathrm{bp}$ at rBNP promoter (data not shown).

\subsection{Constitutively active MKK3b and MKK6b activate rBNP promoter}

Next, the effect of MKK overexpression on BNP reporter activity was studied. Overexpression of either MKK3b(E) or MKK6b(E) significantly induced the rBNP promoter activity (1.6- and 1.7-fold, respectively) and overexpression of WT p38a together with either MKK3b(E) or MKK6b(E) further increased the rBNP promoter activity (Fig. 3A). Overexpression of WT p38 $\beta$ together with MKK6b(E) also further enhanced the rBNP promoter activity, whereas overexpression of WT $\mathrm{p} 38 \beta$ together with $\mathrm{MKK} 3 \mathrm{~b}(\mathrm{E})$ only had a minor effect compared to MKK3b(E) alone (Fig. 3A). The MKK6b(E)-induced rBNP activation was diminished by the mutation of both GATA-4 and AP-1 binding sites. However, MKK3b(E)-induced rBNP activation was independent of GATA-4 and AP-1 binding sites and co-transduction with either of the p38 isoforms did not redirect the signalling to either GATA-4 or AP-1 (Fig. 3B and 3C).

\section{5. $p 38 \alpha$ and $p 38 \beta M A P K$ isoforms regulate cell death in vitro}

Cardiomyocytes transduced with MKK3b(E), MKK6b(E), WT p38 $\alpha$ or WT $p 38 \beta$ were also analysed for apoptotic cell death. Overexpression of MKK3b(E) or MKK6b(E) alone had no effect on the rate of apoptosis, while overexpression of either WT p38 $\alpha$ or WT p38 $\beta$ enhanced apoptosis (1.5- and 1.6-fold, respectively) detected by ELISA. Overexpression of WT p38a+MKK3b(E) and WT p38 $3+$ MKK6b(E) resulted in comparable increases in apoptosis, while combinations WT p38 $\alpha+\mathrm{MKK} 6 \mathrm{~b}(\mathrm{E})$ or WT p38 $\beta+$ MKK3b(E) had no effect (Fig. 4A). Overexpression of p38 $\alpha$ with MKK3b(E) also significantly increased necrotic cell death (Fig. 4B). Necrotic cell death was almost similarly induced by overexpression of MKK6b(E)+ WT p38ß, but this change was not statistically significant (Fig. 4B).

\section{6. $p 38 \alpha$ and $p 38 \beta$ have distinct effects on fibrosis-related and growth factor genes}

To examine whether there are functional differences between $\mathrm{p} 38 \alpha$ and $\mathrm{p} 38 \beta$ in the activation of specific genes related to cardiac fibrosis, a central feature in heart failure (reviewed in Swynghedauw, 1999), cardiomyocytes were transduced with either WT p38 $\alpha$ together with MKK3b(E) or WT p38 $\beta$ with MKK6b(E). Overexpression of $\mathrm{p} 38 \alpha$ isoform (with MKK3b) produced a 3.0-fold increase in CTGF mRNA levels, whereas overexpression of $\mathrm{p} 38 \beta$ with MKK6b had no significant effect (Fig. 5). Similarly, the mRNA levels of both bFGF and MMP-9 were significantly increased (2.0- and 3.3-fold, respectively) by WT p38 $\alpha+$ MKK3b(E), but not affected by overexpression of WT p38 $\beta+M K K 6 b(E)$ (Fig. 5). MMP-2 or COL1A1 gene expression levels were not affected by overexpression of p38 MAPK isoforms. WT p38 $\beta+$ MKK6b(E) significantly decreased the PDGF-A mRNA levels (0.7-fold), while MKK3+p38 $\alpha$ had no effect. Instead, expression of aFGF was significantly decreased in both groups (both to 0.4-fold, Fig. 5).

\section{7. p38 MAPKs regulate cardiac gene expression in vivo}

Finally, adenoviruses expressing MKK3b(E), MKK6b(E), WT p38 $\alpha$ or WT p38 $\beta$ were injected into left ventricular fee wall of adult Sprague-Dawley rats. Three days after injections animals were sacrificed and samples from left ventricles were obtained for RT-QPCR analysis. The mRNA analysis revealed that the overexpression of WT $\mathrm{p} 38 \beta$ with MKK6b(E) resulted in a significant increase in ANP mRNA levels (2.3fold, $P<0.05$ ), whereas other combinations had no significant effect (Fig. 6A). Overexpression of $\mathrm{p} 38 \alpha$ with either of the upstream MKKs led to significant induction of CTGF mRNA levels (Fig. 6B). Overexpression of WT p38a+MKK6b(E) also resulted in an increase in bFGF and MMP-9 mRNA levels (Fig. 6C-D). 
Overexpression of $\mathrm{p} 38 \beta$ together with MKK6b(E) induced a significant increase in CTGF mRNA (Fig. 6B) levels, whereas other fibrosis-related genes were not affected by overexpression of p38 $\beta$ (Fig. 6C-6D).

\section{Discussion}

Given the number of studies focusing on the role of p38 MAPK in the cardiomyocyte intracellular signalling during cardiomyocyte hypertrophy, it is remarkable that no consensus over the functional role of p38 isoforms has been reached. Especially unclear are the differences between the p38 isoforms. In the present work, we studied the involvement of distinct p38 isoforms into the regulation of natriuretic peptide expression as a hallmark of hypertrophic response. Our results suggest that the more important isoform in the regulation of myocyte hypertrophy is $\mathrm{p} 38 \beta$, since only $\mathrm{p} 38 \beta$ isoform significantly activated gene expression of natriuretic peptides ANP and BNP. These results agree with those of Wang et al., who observed hypertrophic response by $\mathrm{p} 38 \beta$ overexpression in cardiomyocytes (Wang et al., 1998). In addition, we found that activation of $\mathrm{p} 38 \beta$ pathway also induced an increase in ANP mRNA levels in vivo. However, both p38 isoforms and MKKs significantly increased the rate of protein synthesis, another important hallmark of cardiac hypertrophy.

Cardiomyocyte hypertrophy can be induced by various GPCR agonists, such as ET-1 (Shubeita et al., 1990). The mechanisms connecting ET-1-induced cytosolic signalling to nuclear targets are not fully understood, though. ET-1 has been reported to activate GATA-4 transcription factor via MAPK-mediated phosphorylation (Kerkela et al., 2002). Here we show that the overexpression of both WT p38 $\alpha$ and WT p38 $\beta$ induce BNP reporter gene transcription, but when treated with hypertrophic agonist ET-1, only DN p38 $\beta$ was sufficient to attenuate the ET-1-induced rat BNP reporter activation. This indicates that p38 $\beta$ isoform plays a key role also in agonist-induced BNP activation.

Our data also shows that there are substantial differences in the activation of downstream mediators GATA-4 and AP-1 by p38 isoforms. GATA transcription factors regulate differentiation, growth and survival of a wide range of cell types (Pikkarainen et al., 2004). Also, apart from regulating embryonic and baseline cardiac gene expression, GATA-4 is involved in inducible cardiac gene expression in response to hypertrophic stimuli. GATA-binding elements have been found in several cardiac specific genes, such as $\alpha$ MHC, ANP and BNP (Pikkarainen et al., 2004). There is evidence suggesting that ERK may function as a regulator of basal GATA-4 DNA binding activity, while p38 may mediate activation of GATA-4 by ET-1 (Kerkela et al., 2002). Transcription factor AP-1, in turn, is known to be a ubiquitous transcription factor whose binding sites are abundant in the promoter region of numerous cardiac genes (Herzig et al., 1997; Grepin et al., 1994). Previous studies have shown that MAPKs represent key upstream signalling molecules in many cell types, and they are able to activate AP-1 complex through a direct phosphorylation of the subunits (Han et al., 1997). However, the role of different isoforms of p38 MAPKs in activating AP-1 has not been elucidated to date. Our current data suggests that overexpression of WT $\mathrm{p} 38 \alpha$ activated the BNP promoter in AP-1 dependent manner, whereas overexpression of WT $\mathrm{p} 38 \beta$ activated the BNP promoter via GATA-4 binding sites. Overexpression of MKK6b(E) activated the BNP promoter via both AP-1 and GATA-4 binding sites, suggesting involvement of both $\mathrm{p} 38 \alpha$ and $\mathrm{p} 38 \beta$ isoforms. Importantly, the induction of the BNP promoter by MKK3b(E) was not dependent on either AP-1 or GATA-4 binding sites indicating that signal was not transmitted either through $\mathrm{p} 38 \alpha$ or $\mathrm{p} 38 \beta$.

p38 MAPK has also been implicated in the regulation of fibrosis (for review see Clerk and Sugden, 2006). Here we found that a number of fibrosis-related genes are differentially regulated by distinct p38 isoforms. CTGF is a growth factor activated during cardiac fibrosis and it has been shown that CTGF is rapidly up-regulated in response to several hypertrophic stimuli, including ET-1, PE, angiotensin II, growth factors and mechanical stretch (reviewed in Matsui and Sadoshima, 2004; Daniels et al., 2009). We show that WT $\mathrm{p} 38 \alpha+\mathrm{MKK} 3 \mathrm{~b}$ (E) overexpression significantly increased CTGF mRNA levels both in vitro and in vivo. MMP-9, another important protein that critically contributes to the re-organization of extracellular matrix (Spinale, 2002), was activated in cultured cells by overexpression of WT p38 $\alpha+\mathrm{MKK} 3 \mathrm{~b}(\mathrm{E})$, but not by WT $\mathrm{p} 38 \beta+\mathrm{MKK} 6 \mathrm{~b}(\mathrm{E})$, whereas in in vivo studies, the overexpression of $\mathrm{p} 38 \alpha$ together with MKK6b(E) was sufficient to induce MMP-9 gene expression. However, there were no differences in COL1A1 mRNA levels in WT p38 $\alpha+M K K 3 b(E)$-transduced cells. Overexpression of $\mathrm{p} 38 \beta$ with MKK6b(E) reduced the mRNA levels of growth factors PDFG-A and aFGF in neonatal cardiomyocytes. Overexpression of $\mathrm{p} 38 \alpha$ with MKK3b(E) also reduced aFGF gene expression but, on the contrary, substantially increased bFGF mRNA levels in vitro and $\mathrm{p} 38 \alpha$ with MKK6b also increased bFGF levels in vivo. These results indicate that 
activation of $\mathrm{p} 38 \beta$ pathway typically elicits inhibitory effects on growth factors, while $\mathrm{p} 38 \alpha$ appears to stimulate the fibrosis-related factors CTGF, MMP-9 and bFGF, suggesting that MKK3 and p38 $\alpha$ may play a critical role in maintaining the plasticity of the heart undergoing fibrotic remodelling process. This is in agreement with Liao et al, who demonstrated that overexpression of MKK3b or MKK6b induces cardiac fibrosis (Liao et al., 2001) as well as with Streicher et al. showing that MKK3b overexpressing transgenic mice exhibit increased cardiac interstitial fibrosis and contractile dysfunction (Streicher et al., 2010) and with Zhang et al. reporting reported reduced cardiac fibrosis in dominant negative $p 38 \alpha$-transgenic mice (Zhang et al., 2003). Instead, following myocardial infarction $\mathrm{p} 38 \alpha+\mathrm{MKK} 3 \mathrm{~b}$ overexpression resulted in reduced apoptosis and reduced fibrosis (Tenhunen et al., 2006), and in pressure overload model cardiac-specific p38 $\alpha$ knock-out mice exhibited dilated cardiomyopathy, increased fibrosis and increased apoptosis (Nishida et al., 2004). The differences between the experimental settings may explain these contradictory findings.

The p38 MAPKs are also known to regulate cardiomyocyte viability. Wang et al. have suggested that while p38 $\alpha$ may have pro-apoptotic function in cardiomyocytes, p38 $\beta$ isoform might function as an antiapoptotic molecule (Wang et al., 1998). Instead, we found that apoptosis was similarly increased by p38 $\alpha$ and $\mathrm{p} 38 \beta$ overexpression, and also by overexpression of $\mathrm{p} 38 \alpha+\mathrm{MKK} 3 \mathrm{~b}(\mathrm{E})$ and $\mathrm{p} 38 \beta+\mathrm{MKK} 6 \mathrm{~b}(\mathrm{E})$, but not by other combinations. Notably, Wang et al. used upstream kinase MKK3b with both $\mathrm{p} 38 \alpha$ and $\mathrm{p} 38 \beta$, which may explain the discrepancy compared to our current study. Both combinations also induced necrotic cell death, although the effect was significant only with p38a+MKK3b(E). Nevertheless, the rate of cell death in WT $\mathrm{p} 38 \alpha+\mathrm{MKK} 3 \mathrm{~b}(\mathrm{E})$ and WT $\mathrm{p} 38 \beta+\mathrm{MKK} 6 \mathrm{~b}(\mathrm{E})$-infected cells was very similar and did not influence the interpretation of the rest of the data.

The results of this study may have immediate therapeutic implications, since there are a number of ongoing randomized clinical trials studying the effects of various p38 MAPK inhibitors (with no distinction between isoforms); (http://clinicaltrials.gov). Most of the trials target inflammatory diseases (rheumatoid arthritis, asthma, chronic obstructive pulmonary disease) but also the role of p38 inhibitors in cancer is under active investigation. Several compounds are in trials targeting p38 MAPK also in cardiovascular diseases, such as acute coronary syndrome (ACS) and inflammatory cardiovascular disorders. For example, a p38 inhibitor SB618323 is developed for treatment of coronary heart disease, and another inhibitor VX-702 is being studied in the treatment of ACS (Lee and Dominguez, 2005; Ding, 2006). Our present results highlight that more information about differences between the distinct p38 isoforms is needed to determine whether the pharmacological manipulation of p38 is useful in the treatment of cardiovascular and other diseases.

In conclusion, the functional complexity and ambiguity of the p38 MAPKs in heart may at least partly be explained by the differences between the p38 isoforms. Our current findings suggest that the effects of p38 $\beta$ are mediated via GATA-4 transcription factor, at least in the context of BNP promoter, whereas effects of $\mathrm{p} 38 \alpha$ are mediated via AP-1 binding site. MKK6-induced BNP promoter activation is mediated by both p38 $\alpha$ and p38 $\beta$, whereas the effect of MKK3 is at least partly independent of downstream MAPKs (Fig. 7A). In addition, we demonstrate that $\mathrm{p} 38 \alpha$ plays a key role in the regulation of cardiac fibrosis, whereas $\mathrm{p} 38 \beta$ regulates the expression of hypertrophy-associated genes ANP and BNP (Fig. 7B). Our data thus suggests that isoform-selective p38 MAPK inhibitors may have distinct effects on the expression of hypertrophyassociated genes and genes involved in cardiac fibrosis.

\section{Sources of funding}

This work was financially supported by grants from the Academy of Finland (Center of Excellence), Sigrid Juselius Foundation, Finnish Foundation for Cardiovascular Research, Emil Aaltonen Foundation, Ida Montin Foundation and Finnish Cultural Foundation.

\section{Acknowledgements}

We thank Marja Arbelius and Sirpa Rutanen for the expert technical assistance. We also thank Dr. VeliMatti Kähäri from University of Turku (Finland) for generously providing recombinant adenoviruses used in this work.

Contributors: This study was designed and supervised by HR and RK; HT and SP were involved in guidance and implementation of study; JR, HP and TK helped in in vivo experimental model; JA analyzed the QPCR data; LK and EK performed the in vitro experiments and analysed the data; EK, RK and HR prepared the manuscript. 


\section{Appendix A. Supplementary data}

Supplementary data associated with this article can be found in the online version.

\section{References:}

Bassi, R., Heads, R., Marber, M.S., Clark, J.E., 2008. Targeting p38-MAPK in the ischaemic heart: kill or cure? Curr. Opin. Pharmacol. 8, 141-146.

Berk, B.C., Vekshtein, V., Gordon, H.M., Tsuda, T., 1989. Angiotensin II-stimulated protein synthesis in cultured vascular smooth muscle cells. Hypertension 13, 305-314.

Braz, J.C., Bueno, O.F., Liang, Q., Wilkins, B.J., Dai, Y.S., Parsons, S., Braunwart, J., Glascock, B.J., Klevitsky, R., Kimball, T.F., Hewett, T.E., Molkentin, J.D., 2003. Targeted inhibition of p38 MAPK promotes hypertrophic cardiomyopathy through upregulation of calcineurin-NFAT signaling. J. Clin. Invest. $111,1475-1486$.

Clerk, A., Sugden, P.H., 2006. Inflame my heart (by p38-MAPK). Circ. Res. 99, 455-458.

Daniels, A., van Bilsen, M., Goldschmeding, R., van der Vusse, G.J., van Nieuwenhoven, F.A., 2009. Connective tissue growth factor and cardiac fibrosis. Acta Physiol. (Oxf) 195, 321-338.

de Bold, A.J., Bruneau, B.G., Kuroski de Bold, M.L., 1996. Mechanical and neuroendocrine regulation of the endocrine heart. Cardiovasc. Res. 31, 7-18.

Derijard, B., Raingeaud, J., Barrett, T., Wu, I.H., Han, J., Ulevitch, R.J., Davis, R.J., 1995. Independent human MAP-kinase signal transduction pathways defined by MEK and MKK isoforms. Science 267, 682685.

Ding, C., 2006. Drug evaluation: VX-702, a MAP kinase inhibitor for rheumatoid arthritis and acute coronary syndrome. Curr. Opin. Investig Drugs 7, 1020-1025.

Grepin, C., Dagnino, L., Robitaille, L., Haberstroh, L., Antakly, T., Nemer, M., 1994. A hormone-encoding gene identifies a pathway for cardiac but not skeletal muscle gene transcription. Mol. Cell. Biol. 14, 31153129.

Gupta, M., Zak, R., Libermann, T.A., Gupta, M.P., 1998. Tissue-restricted expression of the cardiac alphamyosin heavy chain gene is controlled by a downstream repressor element containing a palindrome of two ets-binding sites. Mol. Cell. Biol. 18, 7243-7258.

Han, J., Jiang, Y., Li, Z., Kravchenko, V.V., Ulevitch, R.J., 1997. Activation of the transcription factor MEF2C by the MAP kinase p38 in inflammation. Nature 386, 296-299.

Han, J., Lee, J.D., Bibbs, L., Ulevitch, R.J., 1994. A MAP kinase targeted by endotoxin and hyperosmolarity in mammalian cells. Science $265,808-811$.

Han, J., Lee, J.D., Jiang, Y., Li, Z., Feng, L., Ulevitch, R.J., 1996. Characterization of the structure and function of a novel MAP kinase kinase (MKK6). J. Biol. Chem. 271, 2886-2891.

Han, J., Lee, J.D., Tobias, P.S., Ulevitch, R.J., 1993. Endotoxin induces rapid protein tyrosine phosphorylation in 70Z/3 cells expressing CD14. J. Biol. Chem. 268, 25009-25014. 
Herzig, T.C., Jobe, S.M., Aoki, H., Molkentin, J.D., Cowley, A.W.,Jr, Izumo, S., Markham, B.E., 1997. Angiotensin II type 1a receptor gene expression in the heart: AP-1 and GATA-4 participate in the response to pressure overload. Proc. Natl. Acad. Sci. U. S. A. 94, 7543-7548.

Jiang, Y., Chen, C., Li, Z., Guo, W., Gegner, J.A., Lin, S., Han, J., 1996. Characterization of the structure and function of a new mitogen-activated protein kinase (p38beta). J. Biol. Chem. 271, 17920-17926.

Jiang, Y., Gram, H., Zhao, M., New, L., Gu, J., Feng, L., Di Padova, F., Ulevitch, R.J., Han, J., 1997. Characterization of the structure and function of the fourth member of p38 group mitogen-activated protein kinases, p38delta. J. Biol. Chem. 272, 30122-30128.

Keesler, G.A., Bray, J., Hunt, J., Johnson, D.A., Gleason, T., Yao, Z., Wang, S.W., Parker, C., Yamane, H., Cole, C., Lichenstein, H.S., 1998. Purification and activation of recombinant p38 isoforms alpha, beta, gamma, and delta. Protein Expr. Purif. 14, 221-228.

Kerkela, R., Grazette, L., Yacobi, R., Iliescu, C., Patten, R., Beahm, C., Walters, B., Shevtsov, S., Pesant, S., Clubb, F.J., Rosenzweig, A., Salomon, R.N., Van Etten, R.A., Alroy, J., Durand, J.B., Force, T., 2006. Cardiotoxicity of the cancer therapeutic agent imatinib mesylate. Nat. Med. 12, 908-916.

Kerkela, R., Pikkarainen, S., Majalahti-Palviainen, T., Tokola, H., Ruskoaho, H., 2002. Distinct roles of mitogen-activated protein kinase pathways in GATA-4 transcription factor-mediated regulation of B-type natriuretic peptide gene. J. Biol. Chem. 277, 13752-13760.

Kuwahara, K., Nakao, K., 2010. Regulation and significance of atrial and brain natriuretic peptides as cardiac hormones. Endocr. J. 57, 555-565.

Kyriakis, J.M., Avruch, J., 2001. Mammalian mitogen-activated protein kinase signal transduction pathways activated by stress and inflammation. Physiol. Rev. 81, 807-869.

Lee, M.R., Dominguez, C., 2005. MAP kinase p38 inhibitors: clinical results and an intimate look at their interactions with p38alpha protein. Curr. Med. Chem. 12, 2979-2994.

Li, Z., Jiang, Y., Ulevitch, R.J., Han, J., 1996. The primary structure of p38 gamma: a new member of p38 group of MAP kinases. Biochem. Biophys. Res. Commun. 228, 334-340.

Liao, P., Georgakopoulos, D., Kovacs, A., Zheng, M., Lerner, D., Pu, H., Saffitz, J., Chien, K., Xiao, R.P., Kass, D.A., Wang, Y., 2001. The in vivo role of p38 MAP kinases in cardiac remodeling and restrictive cardiomyopathy. Proc. Natl. Acad. Sci. U. S. A. 98, 12283-12288.

Majalahti-Palviainen, T., Hirvinen, M., Tervonen, V., Ilves, M., Ruskoaho, H., Vuolteenaho, O., 2000. Gene structure of a new cardiac peptide hormone: a model for heart-specific gene expression. Endocrinology 141, 731-740.

Matsui, Y., Sadoshima, J., 2004. Rapid upregulation of CTGF in cardiac myocytes by hypertrophic stimuli: implication for cardiac fibrosis and hypertrophy. J. Mol. Cell. Cardiol. 37, 477-481.

Nishida, K., Yamaguchi, O., Hirotani, S., Hikoso, S., Higuchi, Y., Watanabe, T., Takeda, T., Osuka, S., Morita, T., Kondoh, G., Uno, Y., Kashiwase, K., Taniike, M., Nakai, A., Matsumura, Y., Miyazaki, J., Sudo, T., Hongo, K., Kusakari, Y., Kurihara, S., Chien, K.R., Takeda, J., Hori, M., Otsu, K., 2004. P38alpha Mitogen-Activated Protein Kinase Plays a Critical Role in Cardiomyocyte Survival but Not in Cardiac Hypertrophic Growth in Response to Pressure Overload. Mol. Cell. Biol. 24, 10611-10620.

Ono, K., Han, J., 2000. The p38 signal transduction pathway: activation and function. Cell. Signal. 12, 1-13. 
Pikkarainen, S., Kerkela, R., Pontinen, J., Majalahti-Palviainen, T., Tokola, H., Eskelinen, S., Vuolteenaho, O., Ruskoaho, H., 2002. Decoy oligonucleotide characterization of GATA-4 transcription factor in hypertrophic agonist induced responses of cardiac myocytes. J. Mol. Med. 80, 51-60.

Pikkarainen, S., Tokola, H., Kerkela, R., Majalahti-Palviainen, T., Vuolteenaho, O., Ruskoaho, H., 2003. Endothelin-1-specific activation of B-type natriuretic peptide gene via p38 mitogen-activated protein kinase and nuclear ETS factors. J. Biol. Chem. 278, 3969-3975.

Pikkarainen, S., Tokola, H., Kerkela, R., Ruskoaho, H., 2004. GATA transcription factors in the developing and adult heart. Cardiovasc. Res. 63, 196-207.

Pikkarainen, S., Tokola, H., Majalahti-Palviainen, T., Kerkela, R., Hautala, N., Bhalla, S.S., Charron, F., Nemer, M., Vuolteenaho, O., Ruskoaho, H., 2003. GATA-4 is a nuclear mediator of mechanical stretchactivated hypertrophic program. J. Biol. Chem. 278, 23807-23816.

Ruskoaho, H., 2003. Cardiac hormones as diagnostic tools in heart failure. Endocr. Rev. 24, 341-356.

Saurin, A.T., Martin, J.L., Heads, R.J., Foley, C., Mockridge, J.W., Wright, M.J., Wang, Y., Marber, M.S., 2000. The role of differential activation of $\mathrm{p} 38$-mitogen-activated protein kinase in preconditioned ventricular myocytes. FASEB J. 14, 2237-2246.

Shubeita, H.E., McDonough, P.M., Harris, A.N., Knowlton, K.U., Glembotski, C.C., Brown, J.H., Chien, K.R., 1990. Endothelin induction of inositol phospholipid hydrolysis, sarcomere assembly, and cardiac gene expression in ventricular myocytes. A paracrine mechanism for myocardial cell hypertrophy. J. Biol. Chem. $265,20555-20562$.

Simpson, P., 1985. Stimulation of hypertrophy of cultured neonatal rat heart cells through an alpha 1adrenergic receptor and induction of beating through an alpha 1- and beta 1-adrenergic receptor interaction. Evidence for independent regulation of growth and beating. Circ. Res. 56, 884-894.

Spinale, F.G., 2002. Matrix metalloproteinases: regulation and dysregulation in the failing heart. Circ. Res. 90, 520-530.

Streicher, J.M., Ren, S., Herschman, H., Wang, Y., 2010. MAPK-activated protein kinase-2 in cardiac hypertrophy and cyclooxygenase-2 regulation in heart. Circ. Res. 106, 1434-1443.

Sugden, P.H., Clerk, A., 1998. Cellular mechanisms of cardiac hypertrophy. J. Mol. Med. 76, 725-746.

Swynghedauw, B., 1999. Molecular mechanisms of myocardial remodeling. Physiol. Rev. 79, 215-262.

Tenhunen, O., Rysa, J., Ilves, M., Soini, Y., Ruskoaho, H., Leskinen, H., 2006. Identification of cell cycle regulatory and inflammatory genes as predominant targets of p38 mitogen-activated protein kinase in the heart. Circ. Res. 99, 485-493.

Tenhunen, O., Sarman, B., Kerkela, R., Szokodi, I., Papp, L., Toth, M., Ruskoaho, H., 2004. Mitogenactivated protein kinases p38 and ERK 1/2 mediate the wall stress-induced activation of GATA-4 binding in adult heart. J. Biol. Chem. 279, 24852-24860.

Tenhunen, O., Soini, Y., Ilves, M., Rysa, J., Tuukkanen, J., Serpi, R., Pennanen, H., Ruskoaho, H., Leskinen, H., 2006. p38 Kinase rescues failing myocardium after myocardial infarction: evidence for angiogenic and anti-apoptotic mechanisms. FASEB J. 20, 1907-1909. 
Tokola, H., Salo, K., Vuolteenaho, O., Ruskoaho, H., 1994. Basal and acidic fibroblast growth factorinduced atrial natriuretic peptide gene expression and secretion is inhibited by staurosporine. Eur. J. Pharmacol. 267, 195-206.

Wang, Y., 2007. Mitogen-activated protein kinases in heart development and diseases. Circulation 116, 1413-1423.

Wang, Y., Huang, S., Sah, V.P., Ross, J.Jr, Brown, J.H., Han, J., Chien, K.R., 1998. Cardiac muscle cell hypertrophy and apoptosis induced by distinct members of the p38 mitogen-activated protein kinase family. J. Biol. Chem. 273, 2161-2168.

Zhang, S., Weinheimer, C., Courtois, M., Kovacs, A., Zhang, C.E., Cheng, A.M., Wang, Y., Muslin, A.J., 2003. The role of the Grb2-p38 MAPK signaling pathway in cardiac hypertrophy and fibrosis. J. Clin. Invest. $111,833-841$.

Figure legends:

Fig. 1. p38 $\beta$ regulates mRNA expression of natriuretic peptides and both $\mathrm{p} 38 \mathrm{MAPK}$ isoforms accelerate the rate of protein synthesis. Cultured cardiomyocytes were transduced with adenovirus-combinations WT p38 $\alpha$ + MKK3b(E) or WT p38 $\beta+$ MKK6b(E). RNA was collected 48 hours later and analyzed for gene expression of ANP (A), BNP (B) and $\beta$-MHC (C) by RT-QPCR. The results were normalized to 18S RNA quantified from the same samples and the mRNA levels are presented relative to LacZ-transduced cells (mean \pm SEM of three independent experiments, $\mathrm{n}=7-8$; $* * P<0.01$ and $* * * ~ P<0.001 \mathrm{vs}$. LacZ; ${ }^{\#}, P<0.05$ and \#\#\#, $P<0.001$ vs. p38 $\alpha+\mathrm{MKK} 3$ ). (D) Cultured cardiomyocytes were transduced with recombinant adenoviruses and $\left[{ }^{3} \mathrm{H}\right]$ leucine $(5 \mu \mathrm{Ci} / \mathrm{ml})$ was inserted to culture medium to determine the rate of protein synthesis. Incorporated $\left[{ }^{3} \mathrm{H}\right] l$ leucine was detected by liquid scintillation counter. The data is presented relative to LacZ-transduced cells (mean \pm SEM of one representative experiment performed in triplicates, total $\mathrm{n}=12$; $* P<0.05$, ** $P<0.01$ and $* * * P<0.001$ vs. LacZ).

Fig. 2. Distinct regulation of BNP promoter by p38 isoforms. (A) Cardiomyocytes were transfected with intact rat $(\Delta-534 /+4)$ BNP promoter luciferase construct and subsequently transduced with recombinant adenoviruses DN p38 $\alpha$ or DN p38 $\beta$ and treated with ET-1 (100 nM for 24 hours). Relative levels of luciferase (luc) activity were measured and normalized to pRL-TK control. BNP luc induction is presented relative to LacZ-transduced cells (mean \pm SEM of three independent experiments, $\mathrm{n}=8$; *** $P<0.001$ vs. LacZ; ${ }^{\#}, P<0.05 v s$. LacZ +ET-1). Cultured cardiomyocytes were transfected with intact rat BNP promoter luciferase construct (BNP) (B), and with similar construct carrying a mutation in GATA-4 binding-site (BNP GATAMut) (C) or AP-1 binding-site (AP-1Mut) (D). Subsequently, the cells were cotransduced with WT p38 $\alpha$ or WT p38 $\beta$ and the cell lysates were assayed for luciferace (luc) induction and normalized to pRL-TK. BNP luc activity is presented relative to LacZ-transduced cells (mean \pm SEM of three independent experiments, $\mathrm{n}=19-24 ; * *, P<0.01$ and $* * * P<0.001 v s$. LacZ; $\uparrow, P<0.05 v s$. intact BNP -transfected cells with the same recombinant adenovirus).

Fig. 3. MKK6b regulates BNP promoter through AP-1 and GATA-4 while MKK3b regulates BNP independently of GATA- and AP-1 binding sites. Cultured cardiomyocytes were transfected with intact rat BNP promoter luciferase construct (BNP) (A) or with BNP reporter constructs harbouring the mutation at the binding site of GATA-4 (BNP GATAMut) (B) or AP-1 (AP-1Mut) (C), and cotransduced with recombinant adenoviruses MKK3b(E), MKK6b(E), WT p38 $\alpha$ or WT p38 3 . BNP luciferase (luc) activity is normalized to pRL-TK control vector and presented in proportion to LacZ-treated cells (mean \pm SEM of three independent experiments, $\mathrm{n}=12-20$; **, $P<0.01$ and *** $P<0.001$ vs. LacZ;,$P<0.05$ and ${ }^{\# \#}, P<0.01$ vs. intact BNP transfected cells with the same recombinant adenovirus).

Fig. 4. Both $\mathrm{p} 38$ isoforms induce apoptosis and necrosis. Neonatal rat cardiomyocytes were transduced with adenoviruses WT p38 $\alpha$, WT p38 $\beta$, MKK3b(E), MKK6b(E) or control virus LacZ. (A) The immobilized 
antibody-histone complexes indicating the rate of apoptotic process in cell was determined by spectrophotometer (ELISA ${ }^{\text {PLUS }}$ Cell Death Detection Method). (B) Adenylate kinase release was analyzed from cell culture medium to determine the rate of cytolysis indicating necrotic cell death (by ToxiLight ${ }^{\circledR}$ Bioassay kit). Data is presented relative to LacZ-transduced cells (mean \pm SEM of three independent experiments, $\mathrm{n}=12-20 ; *, P<0.05, * *, P<0.01$ and $* * * P<0.001 v s$. LacZ).

Fig. 5. Effects of p38 $\alpha$ and $\mathrm{p} 38 \beta$ isoforms on the expression of fibrosis-related genes. Cultured cardiomyocytes were transduced with adenovirus-combinations WT p38 $\alpha+$ MKK3b(E) or WT p38 $\beta+$ MKK6b(E). The mRNA levels were determined by reverse transcription and real-time QPCR, and are normalized to 18S RNA quantified from the same samples and presented relative to LacZ-transduced cells (mean \pm SEM of three independent experiments, $\mathrm{n}=4-6$; *, $P<0.05$, $* * P<0.01$ and $* * * ~ P<0.001 v s$. LacZ).

Fig. 6. $\mathrm{p} 38 \alpha$ induces the mRNA expression of CTGF, bFGF and MMP-9 in vivo, whereas $\mathrm{p} 38 \beta$ regulates the transcription of ANP in vivo. Adenoviruses encoding for WT p38 $\alpha$, WT p38 3 , MKK3b(E), MKK6b(E) or LacZ were injected into the left ventricular wall of adult rats. Three days later RNA from left ventricles was analyzed for mRNA levels of ANP (A), CTGF (B), bFGF (C) and MMP-9 (D) by RT-QPCR. The results are normalized to 18S RNA quantified from the same samples and presented relative to LacZ-injected cells (mean \pm SEM, $\mathrm{n}=6-8 ; *, P<0.05$ and $* * P<0.01$ ).

Fig. 7. The functional complexity of p38 in heart. (A) Schematic presentation of p38 MAPK pathway in the regulation of BNP promoter activity. Our results suggest that $\mathrm{p} 38 \beta$ activates BNP through GATA-4, and p38 $\alpha$ via AP-1 transcription factor. Moreover, our results show that MKK3 activates BNP promoter through AP-1 and GATA-4-independent pathway, and hence probably through p38 $\alpha$-independent route. (B)

Schematic presentation of $\mathrm{p} 38$ isoforms in the regulation of cardiac gene expression. Our data indicates that p38 $\alpha$ plays an important role in the regulation of cardiac fibrosis, whereas p38 $\beta$ regulates the expression of hypertrophic genes. 
MS ID\#: MCE-D-10-00530

MS Title: Distinct Regulation of B-type Natriuretic Peptide Transcription by p38 MAPK Isoforms

\section{Highlights:}

$>$ We demonstrate distinct cardiac gene regulation by $\mathrm{p} 38 \alpha$ and $\mathrm{p} 38 \beta .>\mathrm{p} 38 \alpha$ induces BNP transcription through AP-1 and p38 $\beta$ through GATA-4. $>$ p38 $\beta$ is the main regulator of the expression of hypertrophyrelated genes. $>$ p $38 \alpha$ regulates the expression of fibrosis-related genes. 


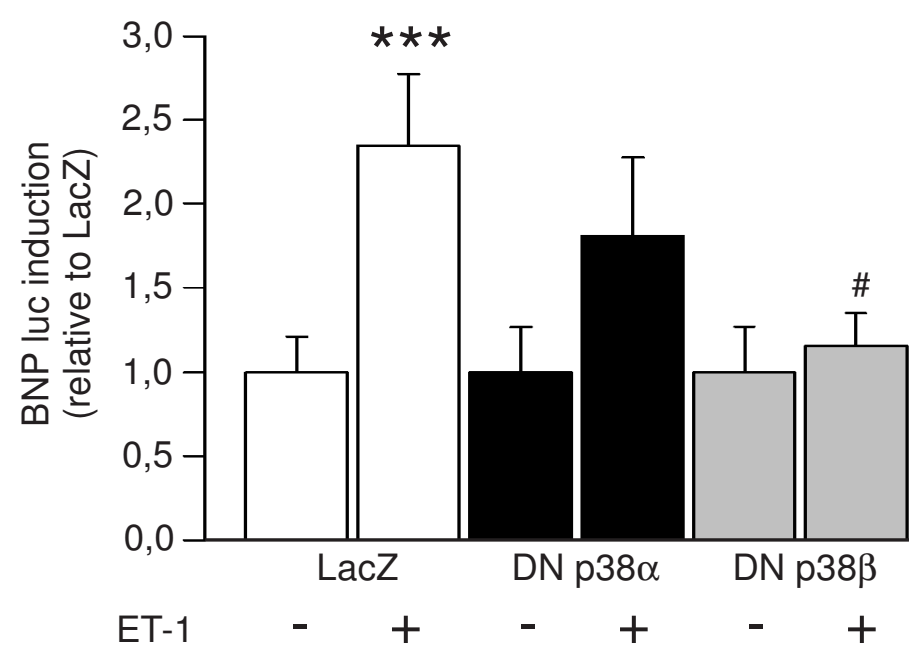

(C)

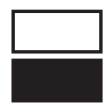

BNP GATAMut

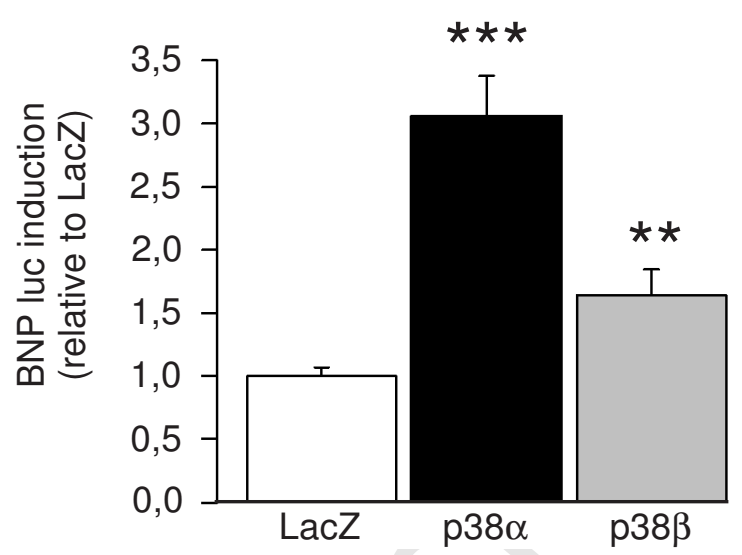

(D)

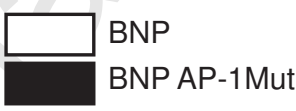

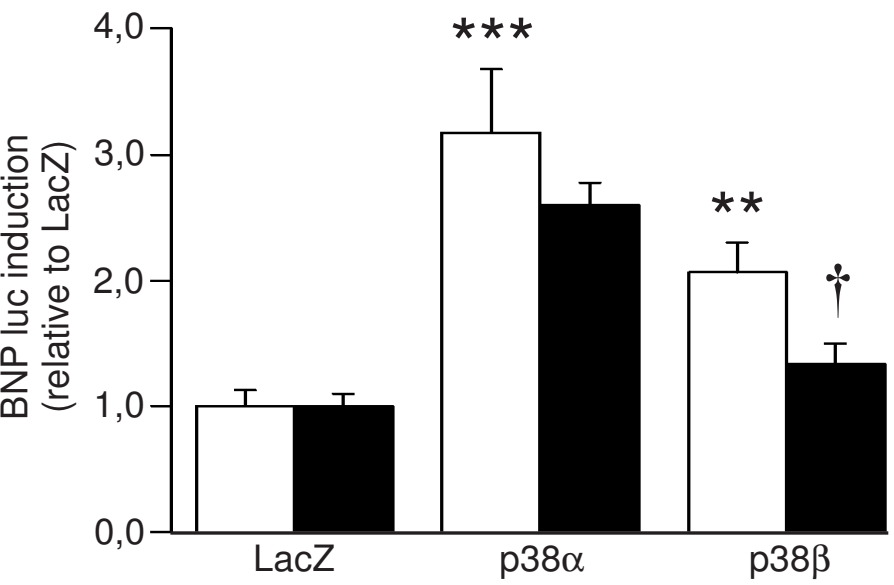

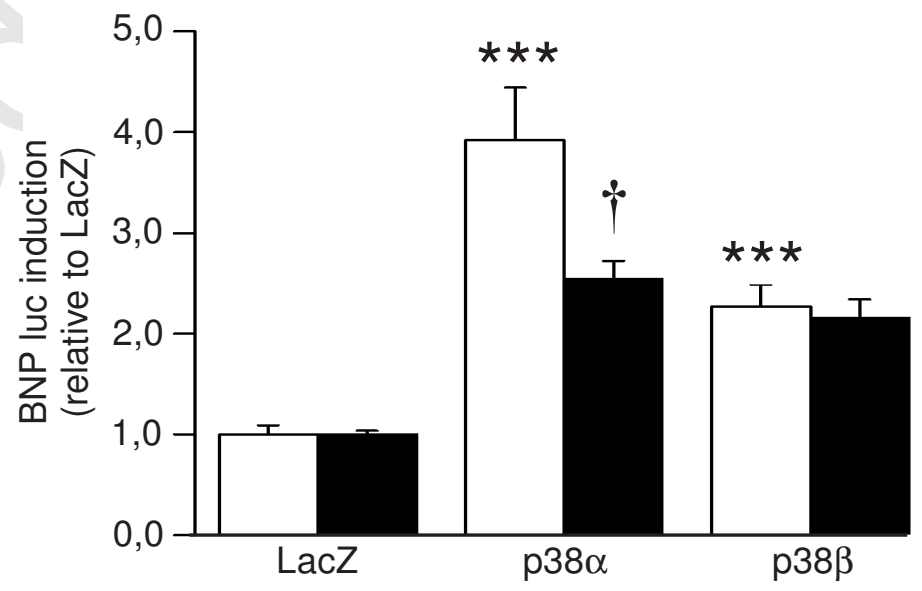


(FAgyre 3

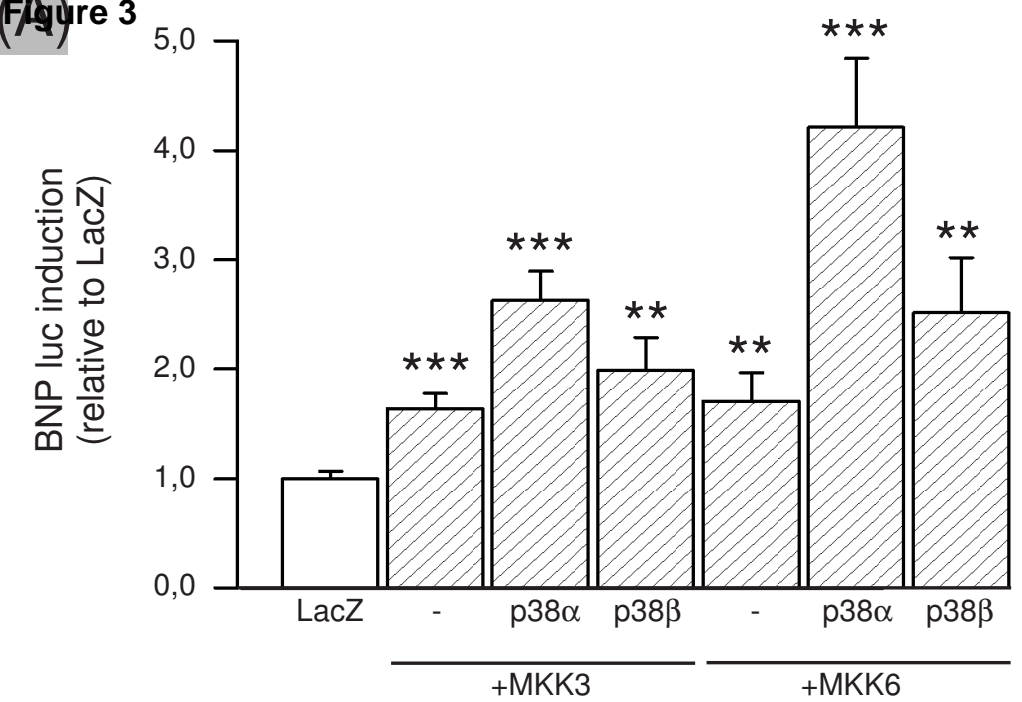

(B)

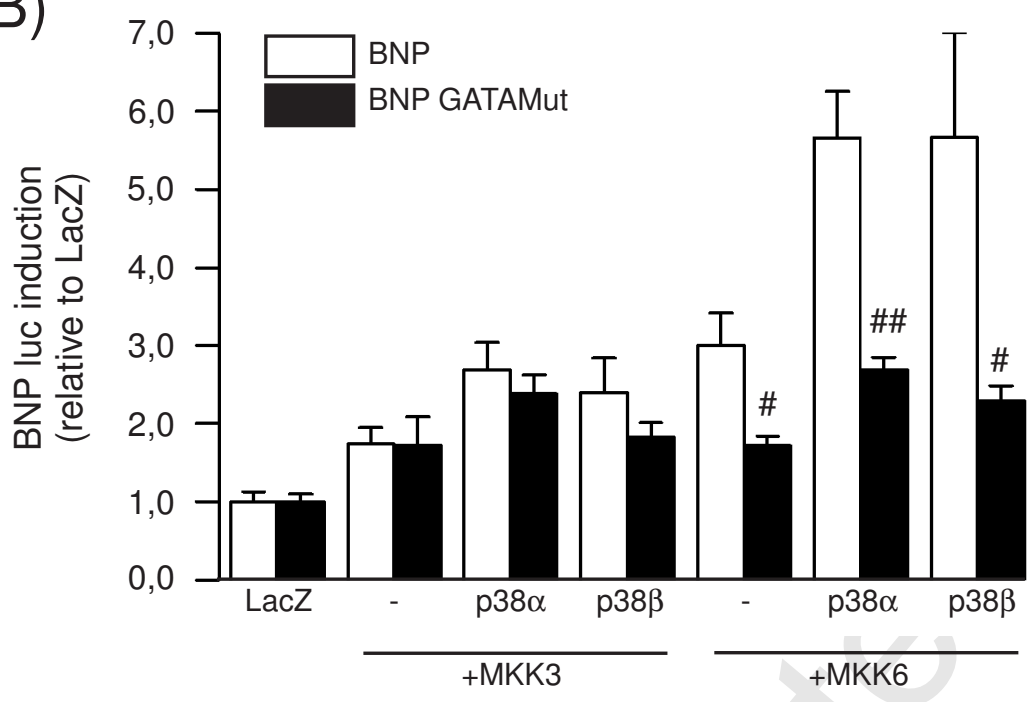

(C

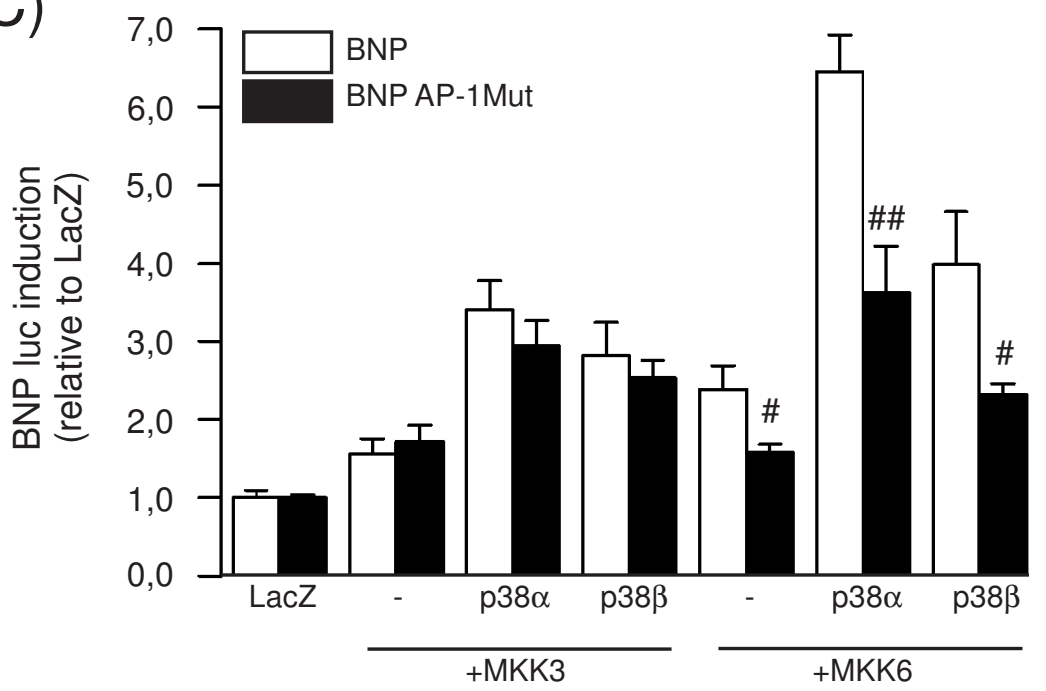




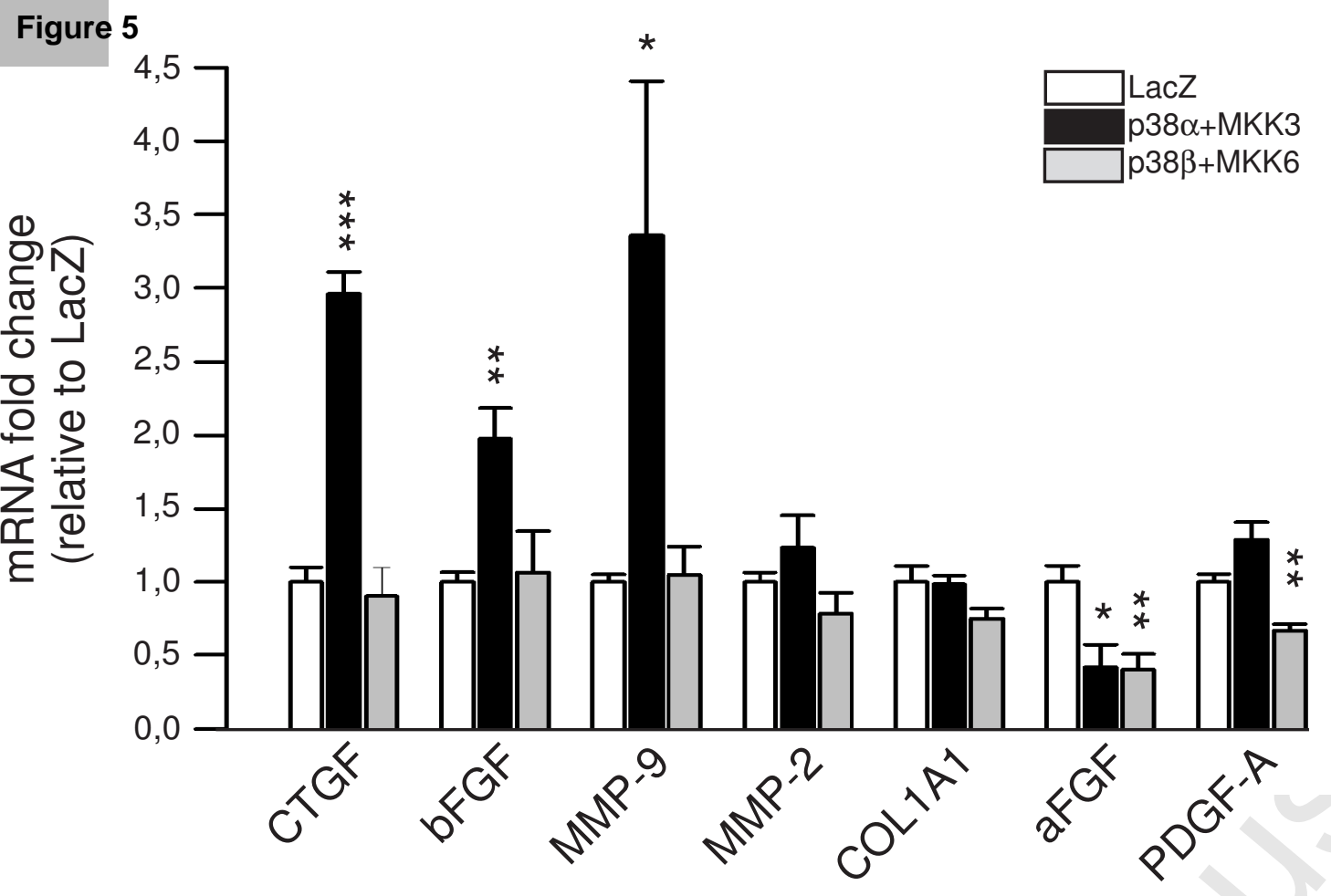




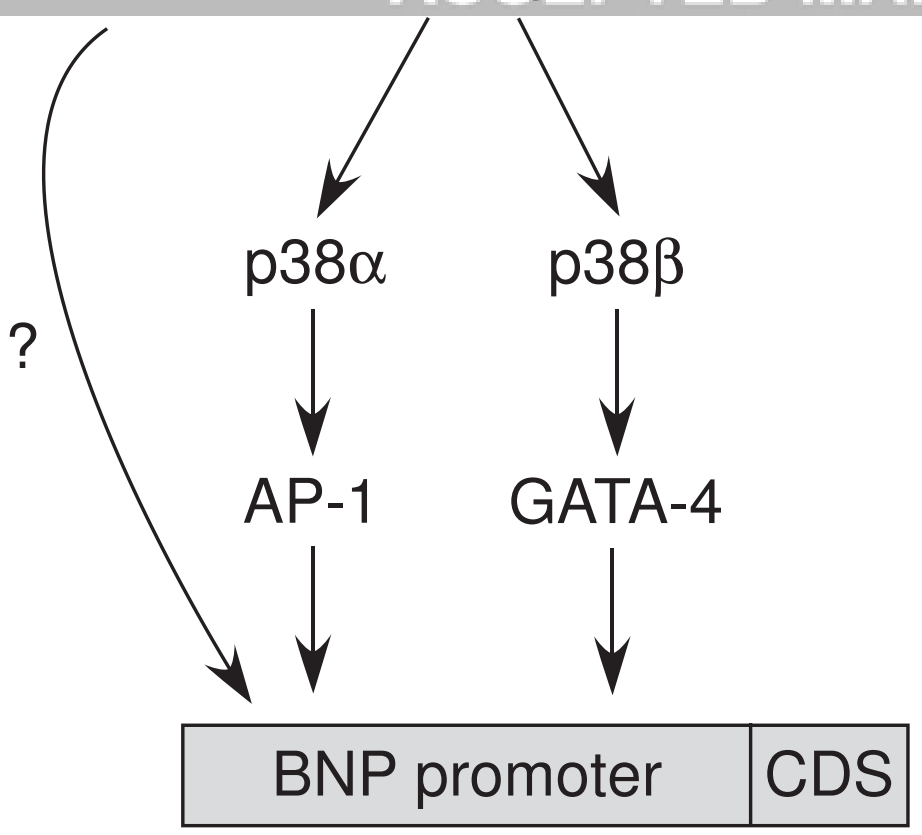

(B)

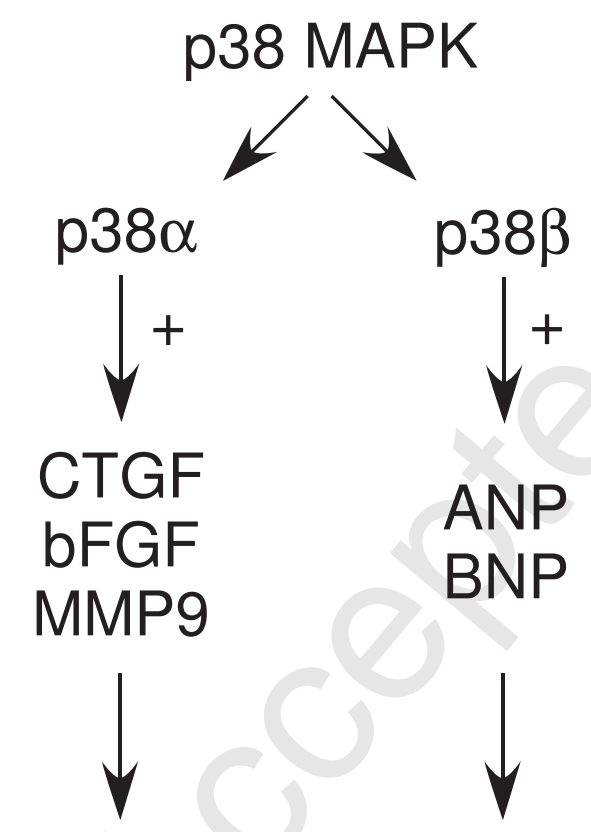

Fibrosis $\uparrow$ Hypertrophy $\hat{\imath}$ 